\title{
Informação e Documento: expressão material no patrimônio
}

\author{
Information and Document: material expression in heritage
}

Maira Cristina Grigoleto

Doutoranda do Programa de Pós-Graduação em Ciência da Informação - UNESP/Marília

E-mail: magrigo@ hotmail.com

\section{Resumo}

A constituição do patrimônio como prática institucional tem chamado a atenção de estudiosos desde o século XVIII e ainda é um campo bastante polêmico, pois muitas questões em torno das ações preservacionistas foram discutidas levando em conta mais os critérios normativos destas práticas do que a compreensão dos mecanismos metodológicos e burocráticos necessários para sua existência. Assim, propomos nesse trabalho enfatizar a importância do universo da produção documental no âmbito institucional da patrimonialização objetivando mostrar o valor que é atribuído à documentação que garante o tombamento como uma expressão material.

Palavras-Chave: Informação. Documento. Patrimônio.

\begin{abstract}
The constitution of the heritage as an institutional practice has called attention of researchers since the eighteenth century. And it is still a field very controversial, because many issues from preservationist actions were discussed considering more the normative criteria of these practices than the understanding of the methodological and paperwork mechanisms necessary for their existence. Therefore, we propose in this paper to emphasizing the importance of the documental production universe under the institutional patrimonialization aiming to show the value that is assigned to the documentation that ensures the listing of buildings as a material expression.
\end{abstract}

Keywords: Information. Document. Heritage.

\section{Introdução}

A proposta desse texto é apresentar a importância que atribuímos ao documento e à informação para constituição do patrimônio, a partir do pressuposto de que qualquer coisa pode ser informativa, ter um valor informativo, mas somente os documentos de arquivo é que podem atribuir a estas diversas coisas, um valor testemunhal e científico. Consideraremos também a visão de Frohmann (2006) ${ }^{1}$ de que a materialização da informação por meio da documentação pode identificar os campos de força - institucional, tecnológico, político e

\footnotetext{
${ }^{1}$ FROHMANN, B. O caráter social, material e público da informação na contemporaneidade. In: ENCONTRO NACIONAL DE PESQUISA EM CIÊNCIA DA INFORMAÇÃO, 7., 19 a 22 nov. 2006, Marília. Anais... Marília. (Publicado em CD-ROM).
}

InCID: R. Ci. Inf. e Doc., Ribeirão Preto, v. 3, n.1, p. 57-69, jan./jun. 2012. 
cultural - que configuram características sociais e públicas da informação na atualidade (apud LARA; ORTEGA, 2008, p. 6).

Como Lara e Ortega pontuam, Frohmann ao aproximar-se de Foucault considera o papel significante da documentação como resultado de um processo que envolve indivíduos e circuitos específicos institucionais, dentro de uma escrita disciplinar. É por esta visão que compreende as práticas documentárias como procedimento que fornece "à informação peso, massa, inércia e estabilidade que materializam a mesma a tal ponto que podem configurar profundamente a vida social" (LARA; ORTEGA, 2008, p. 6).

Os documentos oficiais e não oficiais que compõem os processos de tombamento são criados e arrolados para atender aos interesses dos órgãos preservacionistas e de seus conselheiros, na tentativa de explicar e explicitar alguns atributos dos bens que estão em processo de análise nas instituições preservacionistas estatais. Portanto, a finalidade desses processos é atingir, através do registro de informações, a credibilidade necessária para transformar um bem em patrimônio. As bases jurídicas são, deste modo, o que norteia e normatiza a construção dos documentos e sua adequada inserção nos processos de tombamento.

Burke (2003), ao tratar a cidade como uma fonte de informação sobre si mesma, diz que ela produz volumes crescentes de si. Num sentido mais amplo, podemos concluir que os "volumes crescentes" mencionados são os documentos gerados a partir dos conteúdos informacionais, inscritos nas superfícies das cidades. De diversas tipologias e atendendo as mais variadas funções, os documentos representam a intenção das sociedades de registrar proeminências de suas e outras épocas, seja para organizar as atividades cotidianas ou mesmo para perpetuar características de um tempo. Por meio desta visão, os patrimônios são um dos tantos produtos de uma cidade, gerados a partir do registro de informações específicas, que são a representação dos valores outorgados aos bens materiais e imateriais.

Os processos de tombamento garantem, então, a ativação das informações existentes nos bens móveis e imóveis, materiais e imateriais. Um edifício, transformado em patrimônio, não foi concebido para transmitir informações, mas quando lançamos questionamentos sobre ele e encontramos respostas - que se tornam a base para institucionalização de uma história ou memória - transformamos este objeto em documento(s). 
Para Meyriat (1981, p. 52-54) ${ }^{2}$, todo objeto pode vir a ser um documento. O desejo de obter informação é um elemento necessário para que um objeto seja considerado como documento, ainda que o desejo de seu criador tenha sido outro. O documento não é um dado, mas o produto de uma vontade, aquela de informar ou de ser informado já que o desejo de fornecer informação pode não ter resposta do destinatário (apud LARA e ORTEGA, 2008, p. 4). Assim sendo, o documento tem a função de prova e de suporte de informação que a fixa, podendo ser 'produzido intencionalmente' e/ou ter uma função atribuída. Portanto, se todo objeto pode vir a ser um documento, não quer dizer que todo objeto tem por função ser suporte de informação, mas esta pode ser uma de suas funções. Ou seja, se o usuário faz o documento, dizemos que os usuários são todas as pessoas envolvidas nos processos de produção e uso da informação.

\section{O documento e a constituição do patrimônio}

Ao colocarmos estas questões no âmbito da constituição do patrimônio, dizemos que a intencionalidade no percurso da geração das informações presentes nos processos de tombamento pode garantir a transformação e representação de diferentes tipos de objetos em documento(s). A formalidade dos atos escritos, a articulação dos discursos, as evidências apresentadas, as informações imprescindíveis para que um testemunho seja confiável e efetive uma ação, configuraram nossas principais preocupações.

Compreendemos também que estas intencionalidades, presentes nos percursos de geração dos documentos e no registro de informações que se tornam imprescindíveis para que um testemunho seja confiável e efetive uma ação são peças fundamentais, tanto para o ato do tombamento, quanto para a transformação da natureza original dos bens. Costumamos dizer que o tombamento modifica a natureza dos objetos, pois tem a força de desviá-los de seus usos anteriores, no momento em que lhes imprime novos significados e novos usos (exibição, memória, etc). Para Rubino (1992), cada documento é um dado etnográfico que fala simultaneamente de si, de seu contexto, das condições que o produziram, das que fizeram com que ele se tornasse um documento de pesquisa.

Por este pensamento, achamos coerente retomar algumas abordagens de Frohmann que deslocou o foco do questionamento 'o que é informação?' para 'como se constitui a

\footnotetext{
${ }^{2}$ MEYRIAT, J. Document, documentation, documentologie. Schéma et Schématisation, $2^{\circ}$ trimestre, n. 14 , 1981, p. 51-63.
}

InCID: R. Ci. Inf. e Doc., Ribeirão Preto, v. 3, n.1, p. 57-69, jan./jun. 2012. 
impressão da informação?' e apontou a análise da reificação dos sentidos fornecidos historicamente pelas próprias práticas sociais com a organização material de formas documentais. Frohmann $(2006)^{3}$ assinala que existe uma dupla materialidade do documento: seu engajamento institucional - passível de migração interinstitucional, como a relação textual entre a academia e o aparato jurídico - e a combinação entre enunciação e práticas sociais e públicas, por seu poder de gerar efeitos. Para o autor, o documento é o fato, ou ainda, é $o$ ato - instituidor, institucionalizado, formal, legitimado (apud FREITAS, 2008).

Logo, consideramos que as informações presentes em processos de tombamento são, de certa forma, a tradução e a representação dos diplomas legais e dos mecanismos utilizados pelo estado para a construção de um campo do saber definidor de critérios que orientam a elaboração de documentos administrativos, no intuito de conferir-lhes o poder de outorgar uma autonomia legal e probatória a um bem e instituí-lo como patrimônio. Portanto, o patrimônio não existe no abstrato, mas nas informações - permeadas de valores ou mesmo valorativas - registradas em documentos que são exigidos nas diferentes instâncias burocráticas pelas quais tramitam os processos de tombamento.

Compreendermos, então, que os documentos, a informação materializada institucionalmente, são recursos primordiais para revelação de campos de força que geram ou são representações de práticas sociais e culturais concretas.

Segundo Deleuze, para Foucault

tudo é prática; mas a prática do poder permanece irredutível a toda prática do saber. Para marcar essa diferença de natureza, dirá Foucault que o poder remete a uma "microfísica". Com a condição de não entendermos "micro" como uma simples miniaturização das formas visíveis ou enunciáveis, mas como um outro domínio, um tipo de relações, uma dimensão de pensamento irredutível ao saber: ligações móveis e não-localizáveis (DELEUZE, 2005, p. 81).

\section{Patrimônio: um campo de forças}

Para Frohmann (2001, p. 5-7), o interesse de Foucault não era na documentação como um meio de comunicação de informação, mas como um revezamento de poder, gerador e formador, pelo qual os indivíduos são construídos. Segundo Foucault, a base para a

\footnotetext{
${ }^{3}$ FROHMANN, B. O caráter social, material e público da informação na contemporaneidade. In: ENCONTRO NACIONAL DE PESQUISA EM CIÊNCIA DA INFORMAÇÃO, 7., 19 a 22 nov. 2006, Marília. Anais... Marília. (Publicado em CD-ROM).
}

InCID: R. Ci. Inf. e Doc., Ribeirão Preto, v. 3, n.1, p. 57-69, jan./jun. 2012. 
materialidade da enunciação é a institucionalização. Isto porque, uma enunciação emerge por meio de várias redes relacionais, de campos de uso e está em constante transformação. Sua materialidade é constituída como decorrência de interesses variados, de desafios e lutas, de apropriações e rivalidades.

O autor considera ainda (FROHMANN, 2007, p. 86) que para Deleuze não é só o objeto ou o fenômeno em si uma força, mas tanto um quanto o outro é sempre relatado por outra força. Por essa ótica, conclui-se que não há nenhum evento, fenômeno, palavra ou pensamento que não tenha um senso múltiplo. Esta visão leva-nos a conceber que os elementos de cultura não são uma força em si e, portanto, que não são considerados como elementos viáveis de serem preservados e mantidos para as futuras gerações pelos atributos e valores que emergem naturalmente em sua própria existência. Nesse sentido, o que pode ser preservado são os valores e funções atribuídas às coisas, para e por uma sociedade, em momentos históricos específicos.

A ideia de preservação da memória de alguns fatos ou da preservação de objetos é uma construção histórica, social, institucional que existe somente porque em dados momentos foram produzidos registros que explicitaram a importância destes bens para uma sociedade, recurso indispensável para garantir a preservação tanto física quanto valorativa das coisas institucionalmente. As ações e os objetos, em sua identidade própria, não são os elementos de interesse para preservação. O que torna um objeto de interesse para preservação são os elementos que, ao longo dos tempos, fizeram com que ele se tornasse ponto de referência para uma sociedade.

Essas questões ajudam-nos a olharmos de forma diferenciada para a constituição do patrimônio institucional; tratando-o como uma prática existente somente por meio da materialização de informações, valores e funções que são encontradas ou que se pretende atribuir aos bens. É somente pela forma como os elementos de informação e os valores são registrados, em documentos burocráticos e institucionais, que podemos pensar no patrimônio e na sua constituição, na preservação de bens culturais e na manutenção de pontos de referência em dadas sociedades e momentos históricos.

Nessa perspectiva, as instituições preservacionistas atuam com o processamento de informações, com o registro de informações, com a elaboração de documentos patrimoniais. Uma documentação que garante a recuperação, criação e o registro de conteúdos informacionais necessários para justificar os interesses pela preservação de bens culturais e

InCID: R. Ci. Inf. e Doc., Ribeirão Preto, v. 3, n.1, p. 57-69, jan./jun. 2012. 
sustentar, através de documentação probatória (valorativa e de valor) o ato preservacionista outorgado por meio do tombamento.

Ao apresentarmos essa visão sobre o patrimônio, enfatizamos a colocação de Arantes (1987, p. 52) de que “(...) no momento em que patrimoniamos bens reinventamos as coisas e o passado, recriando sentidos, introduzindo novos pensamentos em dadas sociedades". Assim, é possível verificarmos que a constituição do patrimônio não é um processo natural, mas um processo histórico e permeado de interesses; uma invenção ou reinvenção. Por invenção devemos entender a proposta de instituir novos pensamentos e relações com os objetos do passado por meio da atribuição de valores; uma maneira de inventarmos ou (re) inventarmos as coisas.

\section{O documento e o tempo}

Tais constatações nos chamam particularmente a atenção, pois permitem, entre tantas outras coisas, compreendermos que é por meio das palavras registradas em documentos institucionais que o passado pode ser reinventado; que certas memórias, objetos e elementos de uma sociedade podem ser preservados por meio de atos institucionais.

Em analogia a ideia de Foucault sobre a construção do "homem" e do indivíduo no século XIX, Frohmann esclarece essa questão dizendo tal emergência é resultado de massas documentais. Uma vez que a escrita, não somente captura, fixa e descreve os indivíduos, mas os constrói por meio de aparatos disciplinares transformando-os em objetos do conhecimento (FROHMANN, 2001, p. 7, tradução nossa).

Se o patrimônio só existe porque em dados locais e momentos históricos foi possível atribuir valores a determinados bens precisamos, pois, compreender como isto foi processado no interior das instituições preservacionistas. Um caminho é pensamos no patrimônio por meio dos atributos dos objetos/bens, da relação e representatividade que estes possuem nas sociedades ou pela importância destes para preservação de alguns itens que denotem os processos percorridos pela humanidade. Esses itens podem ser compreendidos como as características históricas, arquitetônicas, artísticas, arqueológicas, enfim, as categorias ou os critérios de valores possíveis de serem relacionados a alguns bens. Dentro desses parâmetros podemos enxergar que estas características representam o patrimônio ou permitem a sua existência, mas o que garante essa emergência é o reconhecimento destes elementos, a forma

InCID: R. Ci. Inf. e Doc., Ribeirão Preto, v. 3, n.1, p. 57-69, jan./jun. 2012. 
como alguns destes critérios de valor foram reconhecidos, considerados, circunscritos no processo de constituição do patrimônio e explicitados como valores indispensáveis pelos agentes preservacionistas.

Um pensamento diferente do que costumamos ter de que é um bem e seus atributos em si que geram a produção da documentação patrimonial para, simplesmente, registrar e perpetuar o que já é algo natural nas coisas. Ou seja, que os elementos físicos e abstratos inerentes aos objetos é que naturalmente fazem o patrimônio. Todavia, um bem só será patrimônio no momento em que alguns destes itens - e elementos que talvez nunca tenham existido - sejam reconhecidos e apresentados dentro de um universo institucional, dentro de enquadramentos categóricos, a partir de um trabalho científico que gere um produto do conhecimento científico. Outros elementos podem até ter representatividade e reconhecimento em outras esferas, mas somente o valor que é registrado dentro de uma esfera institucional de poder, por meio de procedimentos documentais específicos, é que permite a emergência de certos itens de informação necessários e possíveis de serem arrolados nos autos de um processo para patrimonialização.

\section{O valor de um bem e as ações institucionais}

A questão que deve ficar clara é que os valores, as categorias e critérios de valor relacionados às coisas, os olhares que lançamos sobre os objetos e as coisas do passado não são naturalmente intrínsecas; são atribuições possíveis a partir de um olhar institucional, de questionamentos e interesses contemporâneos a toda elaboração de documentos que tem o poder de revelar ou construir tais características. Como pontua Foucault, a verdade é uma construção desse mundo, produzida através de múltiplas coerções, elaboradas através de mecanismos disciplinares, de técnicas, procedimentos, que percorrem instâncias garantindo o estatuto de verdade a certas coisas (FOUCAULT, 1979, p. 12).

Nesse ponto podemos afirmar que um bem arquitetônico, por exemplo, não possui valor/valores por si só. O que temos que compreender é que estes foram atribuídos da mesma forma que seus usos e funções em dadas sociedades; fazem parte de um regime de verdade, construído e institucionalizado. Não é em qualquer ou em toda historicidade que um bem sustente esses valores ou mesmo uma única relação.

Como apresenta Deleuze,

InCID: R. Ci. Inf. e Doc., Ribeirão Preto, v. 3, n.1, p. 57-69, jan./jun. 2012. 
as visibilidades, por sua vez, por mais que se esforcem para não se ocultarem, não são imediatamente vistas ou visíveis. Elas são até mesmo invisíveis enquanto permanecermos nos objetos, nas coisas ou nas qualidades sensíveis, sem nos alçarmos até a condição que as abre. E as coisas se fecham de novo, as visibilidades se esfumam ou se confundem, a tal ponto que as "evidências" se tornam incompreensíveis a uma outra época (DELEUZE, 2005, p. 66).

Para exemplificar a questão das visibilidades, o autor mostrou que se as arquiteturas são visibilidades e locais de visibilidades é porque são agenciamentos de coisas e combinações de qualidades, formas de luz que distribuem o claro e o escuro, o opaco e o transparente, o visto e o não-visto. Portanto, não são meras figuras de pedra, mas complexos de ações e de paixões, de ações e de reações que vêm à luz. Diante disso, cada formação histórica vê e faz ver tudo o que pode, em função de suas condições de visibilidade, da mesma forma como diz tudo o que pode, em função de suas condições de enunciado (DELEUZE, 2005, p. 66-68).

Precisamos entender, pois, que o que garante a preservação e perpetuação de determinados valores e relações com os objetos são as ações institucionais que determinam um olhar específico sobre as coisas - dentro, é claro, dos interesses e normativas de cada instituição ou agente institucional. Segundo Foucault (1979, p. 175-176), o poder é o que reprime a natureza, os indivíduos, os instintos; o poder político é uma forma de reinscrever perpetuamente as relações de força, através de uma espécie de guerra silenciosa, nas instituições, na linguagem e até no corpo dos indivíduos.

Dessa forma, o patrimônio é construído por meio de procedimentos institucionais e através do registro de informações; da elaboração de documentos que comprovem e provem os elementos que as instituições e os agentes preservacionistas pretendem ligar aos objetos para sua transformação em patrimônio. Portanto, é fundamental observarmos a microfísica do poder nas instituições preservacionistas brasileiras, o corpus de poder, os focos de poder, os lugares e não-lugares, o dito e não-dito, as enunciações moldadas por regras e leis, as enunciações influenciadas ou contaminadas por rastros de interesses institucionais, sociais, pessoais e por experiências diversas; as tantas "ligações móveis" e "não-localizáveis". Enfim, é necessário construirmos um caminho viável para entendermos de que forma tais elementos, ora tangíveis ora intangíveis, emergem e podem ser identificados através da análise da documentação patrimonial. Como diz Deleuze (1983, p. 3) ${ }^{4}$, "nós nunca acharemos o senso de algo (de um fenômeno humano, biológico ou então físico) se não soubermos a força que

\footnotetext{
${ }^{4}$ DELEUZE, G. Nietzsche and Philosophy. NY: Columbia University Press, 1983.
}

InCID: R. Ci. Inf. e Doc., Ribeirão Preto, v. 3, n.1, p. 57-69, jan./jun. 2012. 
destina as coisas, que as explora, as possui e as expressa" (apud FROHMANN, 2007, p. 86, tradução nossa).

Em consonância com a visão de Frohmann, verificamos que a documentação patrimonial não é um recurso elaborado simplesmente para registrar ou transcrever o préexistente, mas para construir um campo discursivo capaz de outorgar um ato e sustentá-lo. No entanto, cabe lembrar que não é um ato administrativo qualquer.

Frohmann (2001, p. 7) revisitando Foucault mostra que para o autor o "homem" foi inventado, capturado e fixado em e por meio de massas documentais, sendo, dessa maneira, criatura das práticas que estes documentos trouxeram a existência. $\mathrm{O}$ homem para ele aparece então como um artefato de massas documentais. De forma semelhante, podemos pensar o patrimônio institucionalizado como uma invenção, uma existência possível por ter sido resultado dos registros presentes na massa de documentos que compõe os processos de tombamento.

Outro ponto que desejamos enfatizar é acerca da origem histórica dos documentos patrimoniais. Dizemos que tais documentos já nascem históricos, pois eles são produzidos com o objetivo de alterar o curso natural dos bens, foco de suas deliberações. Esses documentos, provenientes de gestões administrativas, não foram elaborados, necessariamente, para uma utilização posterior - por exemplo, como documentos de pesquisa para estudiosos de diferentes áreas (historiadores, sociólogos, antropólogos, etc). No entanto, o objetivo específico de sua criação, servir como instrumento para valorização e perpetuação de bens, e a finalidade de atender a empenhos institucionais, sociais e culturais faz com que eles se tornem históricos. O tombamento não é um acontecimento natural e, por esta razão, da mesma forma que a emergência de bens patrimoniais é um processo histórico, os documentos que possibilitaram tal incidência também são históricos.

Em uma visão semelhante, Foucault (1979, p. 179-180) mostra que o poder não é um objeto natural, uma coisa; é uma prática social e, como tal, constituída historicamente. Segundo o autor, nas sociedades existem relações de poder múltiplas que atravessam, caracterizam e constituem o corpo social; relações que não podem se dissociar, se estabelecer nem funcionar sem uma produção, acumulação, circulação e funcionamento do discurso. Assim, não há possibilidade de exercício de poder sem que haja certa economia dos discursos de verdade que funcione dentro desta dupla exigência. Somos submetidos pelo poder à produção da verdade e só podemos exercê-lo através da produção da verdade.

InCID: R. Ci. Inf. e Doc., Ribeirão Preto, v. 3, n.1, p. 57-69, jan./jun. 2012. 
Foucault, ao analisar a distinção entre ciência e ideologia, considera que todo conhecimento, científico ou ideológico, só pode existir a partir de condições políticas que formem tanto o sujeito quanto os domínios de saber. Assim, a investigação do saber deve remeter as relações de poder que lhe constituem.

Neste particular, percebemos que tanto os mecanismos quanto a atuação dos profissionais envolvidos no processo de constituição do patrimônio não podem ser entendidas como neutras, mas como resultados dos interesses institucionais e de momentos históricos específicos; como uma forma articulada de exercício de poder.

Deste modo, esses documentos, gerados no processo de constituição do patrimônio, são produtos imperiosos para as seguintes situações: reinvenção do passado, recriação do sentido dos objetos, acréscimos de significados e transformações simbólicas.

A compreensão e interpretação do contexto que cerca a criação dos documentos patrimoniais, o fluxo institucional desta documentação, a resolução do ato, o imperar de discursos, os desdobramentos das palavras escritas e as implicações sociais, históricas e culturais de uma ação. Esses pontos parecem-nos de grande relevância para entendermos a abrangência atingida pelos processos de tombamento e para não naturalizarmos a ideia de patrimônio.

Em outras palavras, os documentos patrimoniais - de importância burocrática, probatória e legal - é que dão lugar ao patrimônio, na medida em que materializam valores materiais e imateriais dos objetos. Podemos dizer, então, que estas instituições, ao criarem um corpus documental em papéis criam um corpus patrimonial, na medida em que dão origem a objetos patrimoniais que se tornam documentos históricos, artísticos, etc.

Heather Macneil (2001, p. 41) diz que uma das características mais difundidas da burocracia é a existência de um sistema de controle baseado em regras que regulam todas as organizações com base no conhecimento técnico e com o objetivo de alcançar a máxima eficiência. Essa premissa é o que garante a confiabilidade nas ações dos burocratas, conquistada pelo registro sistemático de todos os procedimentos realizados para tomada de decisões; documentos que servirão ao interesse, por exemplo, de prestação de contas sobre os recursos por eles utilizados para efetivação de um ato.

Quando propusemos nossa análise tínhamos em mente a importância dos momentos processuais de elaboração de registros, pois compreendíamos, acima de tudo, que a gênese de 
um documento implica tanto a presença de um fato quanto o interesse de manifestá-lo como vontade de dar origem a determinado ato. Segundo Tamayo $(1996)^{5}$, um ato começa sempre com uma declaração ou manifestação de vontade da pessoa - física ou jurídica - que deseja outorgá-lo (apud BELLOTO, 2002, p. 35).

Assim, a manifestação da vontade de tombar um imóvel, de impulsionar uma ação passa a ser circunscrita em uma esfera governamental e administrativa, independente do agente motivador desta necessidade de outorgar um ato administrativo. Desde a sua gênese a documentação patrimonial é construída dentro de uma esfera governamental, mesmo com influências externas, e tende a seguir seu percurso atendendo às imposições necessárias para constituição de uma documentação patrimonial, a qual tem o poder de sustentar uma ação, o registro de um bem em um Livro do Tombo.

Diante dessas discussões, temos uma ótica que busca trazer à luz as relações de força que muitas vezes não são consideradas e nem distintas da própria produção documental; relações formadas e formalizadas sobre estratos burocráticos e, principalmente, sobre estratos que integram e se integram às relações diferenciais de poder. Nossa preocupação foi explicitar que o patrimônio é resultado de lutas que se desenvolvem em torno de focos particulares de poder. Isso não quer dizer que tais focos não tenham sido designados, mas o importante é a consciência dessa existência. A ideia foi enfatizar que o alvo, as lutas e emergências do campo patrimonial estão circunscritas no universo documental das instituições que constroem produtos sociais e mantém a sua existência, legalidade e credibilidade através de elementos concretos, de itens materializados.

\section{Considerações Finais}

A apresentação dessa complexidade simbólica do patrimônio permite o tratamento e utilização da documentação patrimonial não somente como uma fonte de informação mas, sobretudo, como um recurso indispensável para análise de como se pratica o poder no processo de produção documental e no desenvolvimento de práticas preservacionistas para constituição do patrimônio. Como dissemos, a documentação patrimonial não serve para simplesmente transcrever o preexistente, mas para criar um novo elemento cultural a partir de dados e características passíveis de serem enquadradas institucionais. São construções sociais,

5 TAMAYO, A. Segunda parte: Diplomática. In: Archivistica, diplomática y sigilografia. Madrid: Cátedra, 1996, p. 55-270.

InCID: R. Ci. Inf. e Doc., Ribeirão Preto, v. 3, n.1, p. 57-69, jan./jun. 2012. 
agenciamentos sociais fundamentados por meio de campos de saberes; com base em conhecimentos científicos e através de um trabalho científico. Essa documentação emerge devido a condições políticas específicas e com estruturação em regimes de vontade e verdade construídos histórica e institucionalmente.

Ao nos inserirmos nessa discussão teórica e em encaminhamentos práticos sobre a constituição do patrimônio criamos subsídios para pensar outras concepções sobre o documento que se inscrevem na seguinte questão: o documento é o próprio patrimônio ou o patrimônio é uma inscrição documental? Ou, por outro viés, se é possível colocarmos essas duas hipóteses em um mesmo patamar de valor para pensarmos nesta documentação como um agenciamento social, que mantém ou apaga as políticas de formulações de verdades de uma sociedade; uma documentação que permite novas compreensões sobre o universo de sua própria produção documental.

\section{Referências}

ARANTES, Antonio Augusto. Documentos históricos, documentos de cultura. Revista do Patrimônio Histórico e Artístico Nacional, n. 22, p. 48-55, 1987.

BELLOTTO, Heloísa Liberalli. Como fazer análise diplomática e análise tipológica de documentos de arquivo. São Paulo: Arquivo do Estado e Imprensa Oficial do Estado, 2002.

BURKE, Peter. Uma história social do conhecimento: de Gutenberg a Diderot. Rio de Janeiro: Jorge Zahar Ed., 2003.

DELEUZE, Gilles. Foucault. São Paulo: Brasiliense, 2005.

FOUCAULT, Michel. Microfísica do poder. Rio de Janeiro: Graal, 1979.

FREITAS, Lídia Silva de. Tematizando o objeto da Ciência da Informação uma arqueologia da escrita. In: ENCONTRO NACIONAL DE PESQUISA EM CIÊNCIA DA INFORMAÇÃO - ENANCIB, 9., 2008, São Paulo. Anais... São Paulo: ANCIB, USP, 2008. (Publicado em CD-ROM).

FROHMANN, Bernd. Discourse and documentation: some implications for pedagogy and research. Journal of Education for Library and Information Science, Oak Ridge (EUA), v. 42, n.1, 2001.

The role of facts in Paul Otlet's modernist project of documentation. In: RAYWARD, W. Boyd. European modernism and the information society: informing the present, understanding the past. Aldershot, Hants, England; Burlington, VT: Ashgate, 2007. 
LARA, Marilda Lopes Ginez de; ORTEGA, Cristina Dotta. Documento e informação, conceitos necessariamente relacionados no âmbito da Ciência da Informação In: ENCONTRO NACIONAL DE PESQUISA EM CIÊNCIA DA INFORMAÇÃO - ENANCIB, 9., 2008, São Paulo. Anais... São Paulo: ANCIB, USP, 2008. (Publicado em CD-ROM).

MACNEIL, Heather. Trusting Records in a Postmodern World. Archivaria, 51, 2001, p. 3647.

RUBINO, Silvana. As fachadas da história: as origens, criação e os trabalhos do SPHAN, 1936-1967. Dissertação (Mestrado), UNICAMP/IFCH/Antropologia Social, Campinas, 1992.

Artigo submetido em: 28 mar. 2011

Artigo aceito em: 03 nov. 2011 